\title{
Interactive comment on "Modelling Silicate - Nitrate - Ammonium co-limitation of algal growth and the importance of bacterial remineralisation based on an experimental Arctic coastal spring bloom culture study" by Tobias R. Vonnahme et al.
}

Tobias R. Vonnahme et al.

tobias.vonnahme@uit.no

Received and published: 26 November 2020

We want to sincerely thank the reviewer for the very thorough review and believe the suggestions will help to improve the manuscript considerably. We will include all suggestions into a revised version as described in detail in the attached document (point by point response). The comments by referee \#2 are marked in grey and our responses in black. 
subject to the fitting approach and sensitivity analyses. We fitted the model again with a more automated fitting approach and reached better fits for both the G98 and extended EXT model.

Please also note the supplement to this comment:

https://bg.copernicus.org/preprints/bg-2020-314/bg-2020-314-AC2-supplement.pdf

Interactive comment on Biogeosciences Discuss., https://doi.org/10.5194/bg-2020-314, 2020. 